\title{
Validation of Korean Version of the London Chest Activity of Daily Living Scale in Patients With Chronic Obstructive Pulmonary Disease
}

\author{
Jun Tak Choi, MD, Jeong-Hwan Seo, MD, PhD, Myoung-Hwan Ko, MD, PhD, \\ Sung-Hee Park, MD, PhD, Gi-Wook Kim, MD, PhD, Yu Hui Won, MD, PhD
}

Department of Physical Medicine and Rehabilitation, Research Institute of Clinical Medicine of
Chonbuk National University-Biomedical Research Institute of Chonbuk National University Hospital, Jeonju, Korea

Objective To translate the English version of the London Chest Activity of Daily Living scale (LCADL) into a Korean version and to determine the reliability and validity of the Korean version in patients with chronic obstructive pulmonary disease (COPD).

Methods The English version of LCADL was translated into Korean and back-translated into English. Subsequently, the back-translated version was reviewed and compared with the original, and thus the final K-LCADL was obtained. To evaluate the validation of the K-LCADL, patients simultaneously completed a pulmonary function test, a 6-Minute Walk Test (6MWT), and questionnaires, including the modified Medical Research Council (mMRC) dyspnea scale, the Korean version of the St. George's Respiratory Questionnaire (K-SGRQ), the Korean version of the COPD Assessment Test (K-CAT), and the Korean version of the EuroQoL-5 Dimensions (K-EQ-5D). To assess test-retest reliability, the K-LCADL was again administered to the same patients within 2 weeks from initial assessment.

Results A total of 94 patients participated in the present study. The total K-LCADL score was positively correlated with the K-SGRQ $(\mathrm{r}=0.802, \mathrm{p}<0.001)$, the mMRC dyspnea scale $(\mathrm{r}=0.603, \mathrm{p}<0.001)$, and the K-CAT score $(\mathrm{r}=0.714$, $\mathrm{p}<0.001)$, and negatively correlated with the K-EQ-5D ( $\mathrm{r}=-0.764, \mathrm{p}<0.001), 6 \mathrm{MWT}(\mathrm{r}=-0.635, \mathrm{p}<0.001)$, forced expiratory volume in one second $1(\mathrm{r}=-0.416, \mathrm{p}=0.002)$, and forced vital capacity $(\mathrm{r}=-0.397, \mathrm{p}=0.023)$. Intraclass correlation coefficient of the K-LCADL was $0.951(\mathrm{p}<0.001)$.

Conclusion The K-LCADL is a reliable and valid questionnaire for evaluating limitation of activities of daily living in patients with COPD.

Keywords Validation, Chronic obstructive pulmonary disease, Activities of daily living, Dyspnea

Received July 19, 2017; Accepted August 23, 2017

Corresponding author: Yu Hui Won

Department of Physical Medicine and Rehabilitation, Chonbuk National University Medical School, 20 Geonji-ro, Deokjin-gu, Jeonju 54907, Korea. Tel: +82-63-250-2781, Fax: +82-63-254-4145, E-mail: wonyh@jbnu.ac.kr

ORCID: Jun Tak Choi (http://orcid.org/0000-0001-5805-3170); Jeong-Hwan Seo (http://orcid.org/0000-0002-6915-6674); Myoung-Hwan Ko (http:// orcid.org/0000-0002-0566-3677); Sung-Hee Park (http://orcid.org/0000-0002-4743-2551); Gi-Wook Kim (http://orcid.org/0000-0002-1628-8382); Yu Hui Won (http://orcid.org/0000-0003-2007-9652).

@ This is an open-access article distributed under the terms of the Creative Commons Attribution Non-Commercial License (http://creativecommons.org/ licenses/by-nc/4.0) which permits unrestricted noncommercial use, distribution, and reproduction in any medium, provided the original work is properly cited. Copyright $\odot 2018$ by Korean Academy of Rehabilitation Medicine 


\section{INTRODUCTION}

Shortness of breath, the most common symptom of the chronic obstructive pulmonary disease (COPD), severely affects patient's quality of life, and when coupled with fatigue, impairs various functions in activities of daily living (ADL) [1]. Objective measurement of function in ADL is clinically important for understanding the health status of patients. The Modified Barthel Index is most commonly used to assess impairment in various functions in ADL [2]. However, while useful for understanding functional limitations associated with muscular or neural palsy, such as in stroke patients, this index does not consider the shortness of breath. Thus, an instrument that can effectively quantify functional limitations in ADL, associated with shortness of breath, is required to comprehend health status in patients with COPD [3].

There are several questionnaires for assessing ADL in patients with COPD [4-9], of which the London Chest Activity of Daily Living scale (LCADL) is easy to administer and time-saving. The LCADL is a highly valid and reliable method for assessing shortness of breath severity during ADL in patients with COPD [10]. The questionnaire has been translated into many languages, and the validity and reliability of these translated versions have also been verified [1,11-13]. Clinical tools to evaluate the quality of life of Korean patients with COPD have been developed and are being used in clinical and experimental circumstances after validation study $[14,15]$. However, there exists no Korean version of a questionnaire for assessing limitations in ADL due to shortness of breath. Therefore, in the present study, we aimed to translate and adapt a Korean version of the LCADL scale, considering both linguistic and conceptual perspectives, and to evaluate its validity and test-retest reliability.

\section{MATERIALS AND METHODS}

\section{Subjects}

Patients with COPD who visited our hospital, between March 2015 and June 2017, were included in this study. COPD was diagnosed according to the Global Initiative for Chronic Obstructive Lung Disease (GOLD) guidelines $[16,17]$. Participants who had difficulty in completing the 6-Minute Walk Test (6MWT) and those with limitations in ADL due to pain associated with musculoskeletal disease, or other causes, were excluded from the study. Ethical approval was obtained from the Institutional Review Board of Chonbuk National University Hospital (No. CUH 2016-05-025), and all participants provided written informed consent prior to inclusion in the study.

\section{LCADL}

The original LCADL is a 15 -item questionnaire divided into four domains: personal management, household activities, physical activities, and leisure activities. The respondent rates his or her perceived shortness of breath while performing the activity described in each item, on a scale of 0-5 [4]; a higher score indicates greater shortness of breath severity. Total scores range from 0 to 75 , with higher scores indicating greater limitations in ADL due to shortness of breath.

\section{Korean translation of the LCADL}

First, we obtained permission from Garrod et al. [4,10], the original author of LCADL, for the Korean translation of the LCADL. Subsequently, we conducted the translation according to the following process. The LCADL was translated into Korean, and the translated questionnaire was then back-translated into English by a bilingual translator proficient in both English and Korean. The original and back-translated texts were compared, and the Korean translation was modified accordingly. After correcting any problems encountered while administering the questionnaire to a general sample patient population, a pilot study was carried out among patients with COPD. Finally, additional modifications were made to finalize the K-LCADL.

\section{Assessment of K-LCADL}

The K-LCADL was administered to the subjects via interview conducted by a trained rehabilitation doctor. The examiner and the subject sat across each other and the test was performed with a sheet of the questionnaire and a pen. The examiner asked how much feel 'shortness of breath' during activities on the questionnaire and scored according to patient's expression. To evaluate the test-retest reliability of the K-LCADL, the same investigator administered the questionnaire twice to the same patients within 2 weeks from initial assessment. 


\section{Other assessments}

In addition to completion of the K-LCADL, we conducted the following assessments for evaluation and validation of the K-LCADL related to other COPD assessments: pulmonary function test, commonly performed on patients with respiratory diseases, 6MWT, modified Medical Research Council (mMRC) dyspnea scale [18], Korean version of the St. George's Respiratory Questionnaire (KSGRQ), which is a known valid and reliable assessment for quality of life of patients with respiratory diseases [14], Korean version of the COPD Assessment Test (K-CAT) [15], and Korean version of the EuroQoL-5 Dimension questionnaire (K-EQ-5D). To assess the validity of the KLCADL, correlations between the outcomes of the assessment and the K-LCADL were explored. K-SGRQ scores were converted, as per user guidelines, and K-EQ-5D scores were weighted according to health status, as suggested by Kang et al. [19].

\section{Statistical analyses}

Data analysis was carried out using SPSS version 18.0 for Windows (SPSS Inc., Chicago, IL, USA). All variables were assessed for normal distribution using KolmogorovSmirnov test. The numeric variables were presented as means and standard deviations. To assess the validity, Pearson correlation coefficients with other assessments

Table 1. Demographics and baseline clinical characteristics of subjects

\begin{tabular}{|cc|}
\hline \multicolumn{1}{c}{ Characteristic } & Value \\
\hline Age (yr) & $70.95 \pm 0.96$ \\
\hline Gender & 82 \\
\hline Male & 12 \\
\hline Female & \\
\hline Pulmonary function measures & $58.82 \pm 5.81$ \\
\hline FEV $/$ FVC (\% of predicted) & 19 \\
\hline GOLD stage & 20 \\
\hline I & 38 \\
\hline II & 17 \\
\hline III & \\
\hline IV &
\end{tabular}

Values are presented as mean \pm standard deviation or number of subjects.

$\mathrm{FEV}_{1}$, forced expiratory volume in one second; FVC, forced vital capacity; GOLD, Global Initiative for Chronic Obstructive Lung Disease. were calculated. The intra-rater reliability was measured using the intraclass correlation coefficients (ICC), which indicates stability of the instrument if ICC $\geq 0.70$ [20]. A p-value less than 0.05 was considered statistically significant.

\section{RESULTS}

\section{Participant characteristics}

A total of 94 patients ( 82 men and 12 women; mean age, $70.95 \pm 0.96$ years) participated in this study. The proportion of male patients was high. We classified the participants according to GOLD COPD stage. Demographic and clinical characteristics of the study population are shown in Table 1.

\section{Validity of the K-LCADL}

Data from 94 patients with COPD were analyzed to confirm the validity of the K-LCADL. The means of the total K-LCADL scores, as well as four domain scores, are shown in Table 2. The total K-LCADL scores were positively correlated with the K-SGRQ, mMRC, and K-CAT, and negatively correlated with the K-EQ-5D, 6WMD, FEV (\% of predicted), and FVC (\% of predicted) (Table 3 ) in a statistically significant manner.

\section{Intra-rater reliability of the K-LCADL}

We conducted the second assessment within 2 weeks (mean 13.22 \pm 5.1 days after) from initial assessment for evaluating the test-retest reliability by the same investigator. Subjects who did not experience acute exacerbation of COPD and other medical problems were included for a retest, so 33 patients completed the second K-LCADL. Intra-rater reliabilities were high enough for confirming the reliability of the developed questionnaire as a consis-

Table 2. Domain scores of the K-LCADL

\begin{tabular}{lc}
\hline \multicolumn{1}{c}{ Domain } & 1st assessment $(\mathbf{n = 9 4 )}$ \\
\hline Total scores & $28.12 \pm 1.47$ \\
Personal management & $11.36 \pm 0.43$ \\
Household activities & $5.73 \pm 0.63$ \\
Physical activities & $5.54 \pm 0.26$ \\
Leisure activities & $6.58 \pm 0.16$ \\
\hline
\end{tabular}

Values are presented as mean \pm standard deviation. K-LCADL, Korean version of the London Chest Activity of Daily living scale; ICC, intraclass correlation coefficient. 
Table 3. Correlation between the total score of K-LCADL and other measurements and questionnaires in patients with COPD

\begin{tabular}{lccc}
\hline & Value & Pearson R & p-value \\
\hline mMRC & $2.06 \pm 0.10$ & 0.603 & $<0.001^{* *}$ \\
K-SGRQ & $40.36 \pm 1.83$ & 0.802 & $<0.001^{* *}$ \\
K-CAT & $13.40 \pm 0.63$ & 0.714 & $<0.001^{* *}$ \\
6MWT (m) & $325.54 \pm 12.26$ & -0.635 & $<0.001^{* *}$ \\
K-EQ-5D & $0.58 \pm 0.16$ & -0.764 & $<0.001^{* *}$ \\
FEV $_{1}$ (\% of predicted) & $57.12 \pm 2.34$ & -0.416 & $0.002^{* *}$ \\
FVC $(\%$ of predicted) & $70.53 \pm 1.80$ & -0.397 & $0.023^{*}$ \\
\hline
\end{tabular}

Values are presented as mean \pm standard deviation.

COPD, chronic obstructive pulmonary disease; KLCADL, Korean version of the London Chest Activity of Daily living scale; mMRC, modified Medical Research Council; K-SGRQ, Korean version of the St. George's Respiratory Questionnaire; K-CAT, Korean version of chronic obstructive pulmonary disease assessment test; 6MWT, 6-Minute Walk Test; K-EQ-5D, Korean version of EuroQoL-5 Dimension; $\mathrm{FEV}_{1}$, forced expiratory volume in one second; FVC, forced vital capacity.

${ }^{*} \mathrm{p}<0.05,{ }^{* *} \mathrm{p}<0.01$.

tent assessment tool (Table 4).

\section{DISCUSSION}

This study confirmed that the K-LCADL is a valid and reliable questionnaire and is easy to be administered among Korean patients with COPD. To date, there exists no other Korean clinical tool for evaluating limitations in ADL in domestic patients with COPD. In our study, the K-LCADL showed a high test-retest reliability, and a high correlation was observed with traditional scales and questionnaires administered to the patients with respiratory disease. Moreover, our findings are comparable to multiple studies, which have explored the original LCADL [1,11-13]. Apparently, K-LCADL is proposed as a good clinical questionnaire for evaluating limitations in ADL in patients with COPD.

The test-retest reliability of the K-LCADL over repeated administration was observed to be good with ICCs ranging from 0.856 to 0.961 . This result is in concordance with the original LCADL validation study and other crosscultural validation studies [1,11-13]. The household activities value was lower which can possibly be explained by the duty of household activities. This study included
Table 4. Intra-rater reliabilities

\begin{tabular}{|c|c|c|c|}
\hline Dom & $\begin{array}{c}\text { 1st } \\
\text { assessment } \\
(n=33)\end{array}$ & $\begin{array}{c}\text { 2nd } \\
\text { assessment } \\
(n=33)\end{array}$ & ICC \\
\hline Total sc & $23.02 \pm 2.79$ & $21.13 \pm 1.31$ & $0.951^{*}$ \\
\hline Personal ma & $6.36 \pm 1.43$ & $6.03 \pm 1.21$ & $0.961^{*}$ \\
\hline Household activities & $5.88 \pm 1.63$ & $5.15 \pm 1.45$ & $0.856^{*}$ \\
\hline Physical activities & $4.68 \pm 0.66$ & $4.06 \pm 0.53$ & $0.915^{*}$ \\
\hline Leisure activities & $6.18 \pm 0.46$ & $5.41 \pm 0.41$ & $0.955^{*}$ \\
\hline
\end{tabular}

Values are presented as mean \pm standard deviation.

ICC, intraclass correlation coefficient.

${ }^{*} \mathrm{p}<0.001$.

male-dominant subjects and male patients might not perform household activities as daily routine chores in Korea. It signifies that performing household activities depends on personal situations, regardless of dyspnea, patients could or couldn't involve. Apparently, a relatively lower ICC of household activities component in KLCADL is observed.

To demonstrate the validity of the K-LCADL, a total score of the K-LCAL should be in correlation with existing scales and questionnaires administered to patients with respiratory disease. A weak correlation was observed between the K-LCADL score and pulmonary function measures-r=-0.397 for FVC (\% of predicted), $r=-0.416$ for $\mathrm{FEV}_{1}$ (\% of predicted). This result is not in accordance with a previous study [1], and the discrepancy can be explained based on the difference in disease severity of subjects. Against Klijn et al. [1], which involved patients with severe and very severe COPD stage and showed no correlation of $\mathrm{FEV}_{1}$ with LCADL score, patients with mild to very severe stage COPD included in this study. The original LCADL was developed for patients with severe COPD because dyspnea begins to have an impact on ADL with an increase in disease severity. The moderate negative correlation was found between total score of KLCADL and 6MWT ( $\mathrm{r}=-0.635, \mathrm{p}<0.001)$ and this observation might be explained based on the observation that some activities in K-LCADL were never performed by a few patients (score of 0 ), thereby reducing the total score. Carpes et al. [11] showed an improvement in the correlation between LCADL and 6-minute walking distance when using the percentage of the total LCADL score. The negative correlation between 6MWT and K-LCADL implies that patients who have a lower physical fitness feel 
more hindrance in performing functional activities and the results support the validity of the K-LCADL.

COPD is a progressive disease; reduced activity associated with exacerbation of subjective symptoms leads to loss of muscle mass, including respiratory muscle mass, which may, in turn, further exacerbate difficulty in breathing [21]. In patients with respiratory diseases, shortness of breath is the most common reason for hospital attendance, and one of the most important factors limiting ADL [22]. According to Jones et al. [23], shortness of breath is a key determinant of health-related quality of life, and it is strongly associated with severity of disability in patients with COPD. Thus, it is imperative that clinicians treating patients with COPD understand the severity of dyspnea and disability during ADL, as perceived by the patient. In addition to minimizing symptoms, improving the quality of life, and enhancing independence in ADL, while being goals for pulmonary rehabilitation, should also be treatment goals for patients with COPD [24-26]. Thus, it is important to develop accurate tools for measuring the quality of life and functions in ADL $[14,27]$.

LCADL is known as a valid, reliable and responsible questionnaire for assessing ADL in patients with COPD $[4,10]$. Many studies have been carried out to develop a questionnaire or scale for assessing ADL in patients with respiratory disease [4-9]. Among them, Pulmonary Functional Status and Dyspnea Questionnaire (PFSDQ) is not appropriate for assessing elderly or severely impaired patients, because the questionnaire includes questions regarding tasks that are more complex to be carried out by such a category of patients [4,6]. In addition, the modified version of PFSDQ contains many items that are no longer feasible for elderly and severely ill patients $[4,7]$. In case of Nottingham extended activities of daily living, detection of changes in performance in ADL after a pulmonary rehabilitation program is not feasible [4]. We thought that the LCADL will be easy to administer, and elderly and severe patients can effortlessly understand the questionnaire. Also, the LCADL is a well-established tool for evaluating the ability of ADL in patients with COPD, we would like to translate the original LCADL into Korean and assess the performance in ADL of patients with COPD using K-LCADL.

There were several potential limitations in our study. The first limitation of this study is implicated in the analysis of only intra-rater reliability in the reliability study.
As there was no available additional investigator to complete K-LCADL, we could not confirm inter-rater reliability. Secondly, the relatively small number of participants who completed second K-LCADL evaluation may also be considered as a limitation. Third, our study involved patients with various COPD severities ranging from mild to very severe stage, unlike other studies on the original LCADL and other language versions that employed only people with severe COPD $[1,11,12]$. In case of $6 \mathrm{MWT}$, when the patients showed a severe decrease in 6-minute walking distance, they experienced limitation in ADL. Thus, mild degree COPD in patients can be a confounding factor to influence the results. Additionally, it is hypothesized that the presence of a relatively higher proportion of male patients in the present study compared to other studies and who usually marked ' 0 ' in the home activities items of K-LCADL can have a negative effect on the overall score.

In conclusion, this study verified the validity and reliability of the K-LCADL, suggesting that it may be used to assess limitations in ADL caused by shortness of breath in patients with COPD. Furthermore, the K-LCADL is expected to be clinically useful, as it is short and can be completed by the patient without any assistance. We expect this scale to be useful for following-up patients, examining their responses to treatment, and predicting their prognoses through repeated administrations.

\section{CONFLICT OF INTEREST}

No potential conflict of interest relevant to this article was reported.

\section{ACKNOWLEDGMENTS}

This research was supported by a grant of the Korea Health Technology R\&D Project through the Korea Health Industry Development Institute (KHIDI), funded by the Ministry of Health \& Welfare, Republic of Korea (Grant No. HI15C1529).

\section{REFERENCES}

1. Klijn P, Legemaat M, Beelen A, Keimpema Av, Garrod $\mathrm{R}$, Bergsma $\mathrm{M}$, et al. Validity, reliability, and responsiveness of the Dutch version of the London Chest 
Activity of Daily Living Scale in patients with severe COPD. Medicine (Baltimore) 2015;94:e2191.

2. Shah S, Vanclay F, Cooper B. Improving the sensitivity of the Barthel Index for stroke rehabilitation. J Clin Epidemiol 1989;42:703-9.

3. Vitacca M, Paneroni M, Baiardi P, De Carolis V, Zampogna E, Belli S, et al. Development of a Barthel Index based on dyspnea for patients with respiratory diseases. Int J Chron Obstruct Pulmon Dis 2016;11:1199-206.

4. Garrod R, Bestall JC, Paul EA, Wedzicha JA, Jones PW. Development and validation of a standardized measure of activity of daily living in patients with severe COPD: the London Chest Activity of Daily Living scale (LCADL). Respir Med 2000;94:589-96.

5. Yohannes AM, Roomi J, Winn S, Connolly MJ. The Manchester Respiratory Activities of Daily Living questionnaire: development, reliability, validity, and responsiveness to pulmonary rehabilitation. J Am Geriatr Soc 2000;48:1496-500.

6. Lareau SC, Carrieri-Kohlman V, Janson-Bjerklie S, Roos PJ. Development and testing of the Pulmonary Functional Status and Dyspnea Questionnaire (PFSDQ). Heart Lung 1994;23:242-50.

7. Lareau SC, Meek PM, Roos PJ. Development and testing of the modified version of the pulmonary functional status and dyspnea questionnaire (PFSDQ-M). Heart Lung 1998;27:159-68.

8. Morimoto M, Takai K, Nakajima K, Kagawa K. Development of the chronic obstructive pulmonary disease activity rating scale: reliability, validity and factorial structure. Nurs Health Sci 2003;5:23-30.

9. Weaver TE, Narsavage GL, Guilfoyle MJ. The development and psychometric evaluation of the Pulmonary Functional Status Scale: an instrument to assess functional status in pulmonary disease. J Cardiopulm Rehabil 1998;18:105-11.

10. Garrod R, Paul EA, Wedzicha JA. An evaluation of the reliability and sensitivity of the London Chest Activity of Daily Living Scale (LCADL). Respir Med 2002;96: 725-30.

11. Carpes MF, Mayer AF, Simon KM, Jardim JR, Garrod R. The Brazilian Portuguese version of the London Chest Activity of Daily Living scale for use in patients with chronic obstructive pulmonary disease. J Bras Pneumol 2008;34:143-51.

12. Pitta F, Probst VS, Kovelis D, Segretti NO, Mt Leoni
A, Garrod R, et al. Validation of the Portuguese version of the London Chest Activity of Daily Living Scale (LCADL) in chronic obstructive pulmonary disease patients. Rev Port Pneumol 2008;14:27-47.

13. Vilaro J, Gimeno E, Sanchez Ferez N, Hernando C, Diaz I, Ferrerc M, et al. Daily living activity in chronic obstructive pulmonary disease: validation of the Spanish version and comparative analysis of 2 questionnaires. Med Clin (Barc) 2007;129:326-32.

14. Kim YS, Byun MK, Jung WY, Jeong JH, Choi SB, Kang $\mathrm{SM}$, et al. Validation of the Korean version of the St. George's respiratory questionnaire for patients with chronic respiratory disease. Tuberc Respir Dis 2006;61:121-8.

15. Hwang YI, Jung KS, Lim SY, Lee YS, Kwon NH. A Validation Study for the Korean Version of Chronic Obstructive Pulmonary Disease Assessment Test (CAT). Tuberc Respir Dis (Seoul) 2013;74:256-63.

16. Pauwels RA, Buist AS, Calverley PM, Jenkins CR, Hurd SS; GOLD Scientific Committee. Global strategy for the diagnosis, management, and prevention of chronic obstructive pulmonary disease. NHLBI/WHO Global Initiative for Chronic Obstructive Lung Disease (GOLD) Workshop summary. Am J Respir Crit Care Med 2001;163:1256-76.

17. Vogelmeier CF, Criner GJ, Martinez FJ, Anzueto A, Barnes PJ, Bourbeau J, et al. Global strategy for the diagnosis, management and prevention of chronic obstructive lung disease 2017 Report: GOLD Executive Summary. Respirology 2017;22:575-601.

18. Stoller JK, Ferranti R, Feinstein AR. Further specification and evaluation of a new clinical index for dyspnea. Am Rev Respir Dis 1986;134:1129-34.

19. Kang EJ, Shin HS, Park HJ, Jo MW, Kim NY. A valuation of health status using EQ-5D. Korean Health Econ Rev 2006;12:19-43.

20. Terwee CB, Bot SD, de Boer MR, van der Windt DA, Knol DL, Dekker J, et al. Quality criteria were proposed for measurement properties of health status questionnaires. J Clin Epidemiol 2007;60:34-42.

21. Kim HC, Lee GD, Hwang YS. Skeletal muscle dysfunction in patients with chronic obstructive pulmonary disease. Tuberc Respir Dis 2010;68:125-39.

22. Williams SJ, Bury MR. Impairment, disability and handicap in chronic respiratory illness. Soc Sci Med 1989;29:609-16. 
23. Jones PW, Quirk FH, Baveystock CM, Littlejohns P. A self-complete measure of health status for chronic airflow limitation: the St. George's Respiratory Questionnaire. Am Rev Respir Dis 1992;145:1321-7.

24. Travis WD, Costabel U, Hansell DM, King TE, Lynch DA, Nicholson AG, et al. An official American Thoracic Society/European Respiratory Society statement: update of the international multidisciplinary classification of the idiopathic interstitial pneumonias. Am J Respir Crit Care Med 2013;188:733-48.
25. Ries AL, Bauldoff GS, Carlin BW, Casaburi R, Emery CF, Mahler DA, et al. Pulmonary rehabilitation: joint ACCP/AACVPR evidence-based clinical practice guidelines. Chest 2007;131(5 Suppl):4S-42.

26. Bourbeau J. Activities of life: the COPD patient. COPD 2009;6:192-200.

27. Curtis JR, Martin DP, Martin TR. Patient-assessed health outcomes in chronic lung disease: what are they, how do they help us, and where do we go from here? Am J Respir Crit Care Med 1997;156(4 Pt 1):1032-9. 